\title{
CAREERS
}

THUMBS UP Female administrators embrace strategies to retain women in STEM p.567
BLOG Personal stories and careers counselling blogs.nature.com/naturejobs
NATUREJOBS For the latest career

listings and advice www.naturejobs.com

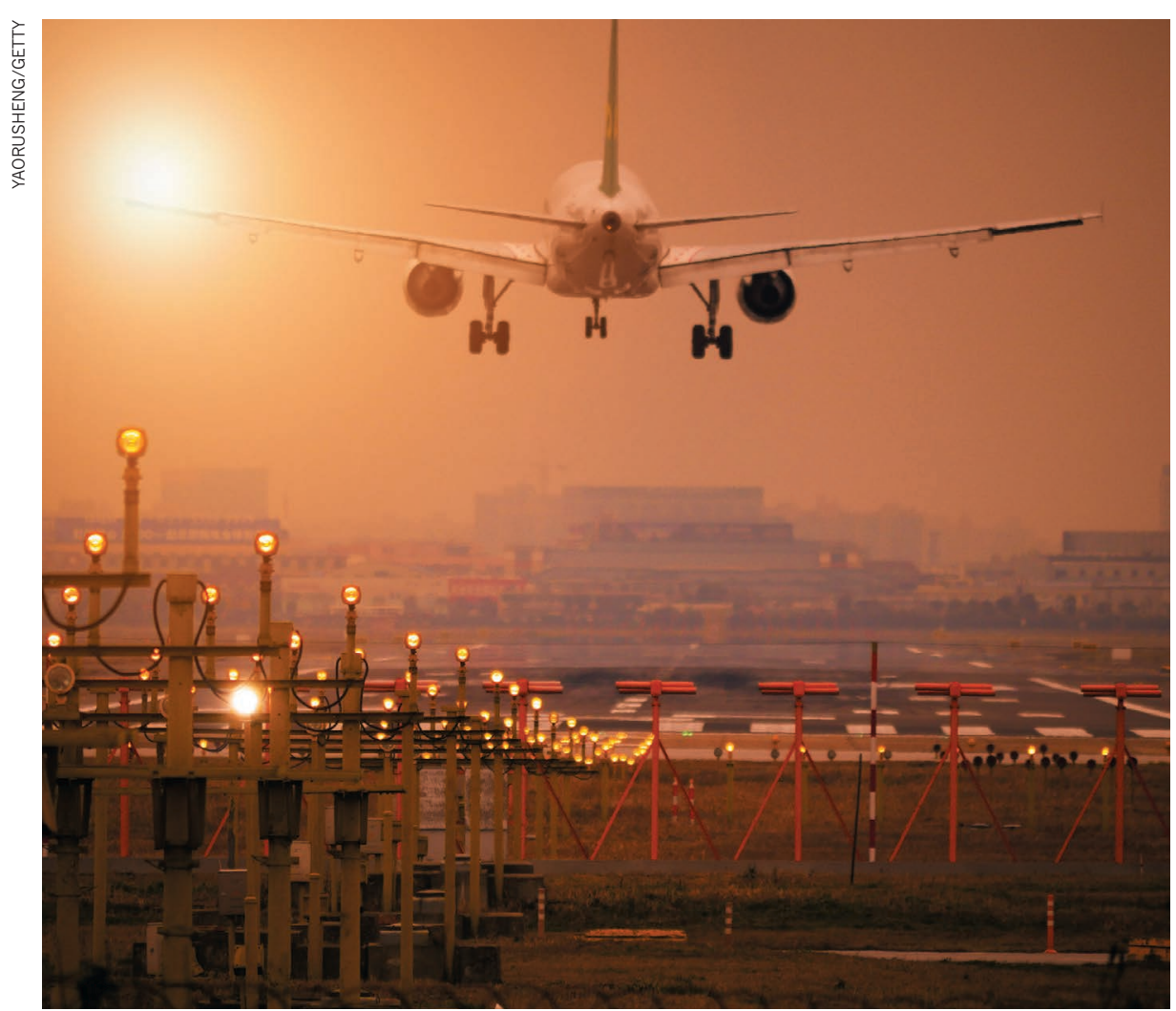

Emissions from air travel constitute a large proportion of many scientists' individual carbon footprints.

SUSTAINABILITY

\section{A greener culture}

\section{Creative minds are shrinking research's big carbon footprint.}

\section{BY JULIA ROSEN}

$\mathrm{I}$ n July 2015, Stephanie and Fraser Januchowski-Hartley left their home in Totnes, UK, and headed for the International Congress for Conservation Biology in Montpellier, France. Instead of catching a flight, they boarded a boat and then made their way across France by bicycle and train, pedalling more than 600 kilometres over 5 days. After the conference, they took a train home.

By eschewing air travel, the pair prevented carbon dioxide emissions of roughly one-half of a metric tonne, and received the Swarovski Optik Green Travel Award from the Society for Conservation Biology, which hosted the meeting. The European branch of the organization is encouraging scientists to shrink their carbon footprints, and Stephanie, now a postdoc studying freshwater conservation at Paul Sabatier University in Toulouse, France, took the challenge to heart. "I feel contradictory if I'm not making some effort in my own life," she says.

She is not alone. Although most researchers say that tackling climate change will require large-scale action from nations and corporations, many individuals are trying to do their own parts. "I think it's important for me as a global citizen," says Erich Osterberg, a climatologist at Dartmouth College in Hanover, New Hampshire. He and his family have taken personal steps such as reducing meat consumption and upgrading to high-efficiency appliances at home. He notes that such actions also help climate scientists such as him to ward off accusations of hypocrisy - that researchers talk the talk but don't walk the walk.

Shahzeen Attari, who studies cognitive science and sustainability at Indiana University Bloomington, has found that scientists' personal behaviour matters to the public. In a 2016 study $^{1}$, she and her colleagues found that audiences perceived carbon-conscious climate scientists as more credible than those with big carbon footprints and, consequently, reported a greater willingness to consider taking climate action in their own lives after hearing those scientists discuss ways to reduce energy use.

Although data are scarce, evidence also suggests that researchers may have larger-thanaverage carbon footprints. For example, 13 conservation scientists who evaluated their own greenhouse-gas emissions found that they were more than 10 times the global average, despite the researchers' efforts to lead low-carbon lives ${ }^{2}$. The greatest source of those emissions was work-related flying.

For many scientists, the high environmental costs of doing science can feel at odds with their values. So, some of them are trying to reduce the carbon footprint of their work by cutting back on air travel, finding creative ways to do fieldwork and 'greening up' their labs. The results often benefit not just the environment, but the science, the budget and even researchers' morale, says Kim Cobb, a climate scientist at the Georgia Institute of Technology (Georgia Tech) in Atlanta. "It's about that engagement that daily reminder that I care."

\section{AIR TIME}

Flying is a routine part of doing science. The Tyndall Centre for Climate Change Research, a consortium in Norwich, UK, surveyed 79 of its researchers in 2012 and found that they flew an average of 2.3 times per year ${ }^{3}$. Often, these flights were to attend conferences and plan meetings - but each had a substantial climate impact. Another study found that presenting a single conference paper results, on average, in about 800 kilograms of $\mathrm{CO}_{2}$ emissions ${ }^{4}$. The researchers also calculated average emissions for conference-paper presentations in popular but non-central locations such as Hawaii (1,290 kg per paper), as well as for scientists travelling from the Southern Hemisphere (between 1,400 and $1,900 \mathrm{~kg}$ per paper). One team notes that a trans-Atlantic flight produces emissions roughly equivalent to a year of commuting 25 kilometres round trip each day by car $^{5}$, an estimate that aligns well with US 
- Environmental Protection Agency data.

Researchers make up a small proportion of air travellers, and aviation emissions account for only $2 \%$ of carbon dioxide from human sources. But those emissions have been steadily growing, and flying often constitutes the biggest chunk of an individual's carbon footprint - two-thirds, offers the biggest opportunity for reducing personal climate impacts (see 'Flight emissions').

Cutting back on conference travel or choosing low-carbon alternatives to flying are good places to start, says Parke Wilde, a food economist at Tufts University in Boston, Massachusetts. "It would not be possible to preserve what's important in our academic life without some flying," he says. "The question is about how and in 2015 he launched a petition aimed at persuading universities and professional societies to set reduction targets for air travel.

Wilde does not fly, but he doesn't expect everyone to follow his lead. Instead, he encourages researchers to strive to cut their flying in half. He advises them to prioritize the most important conferences, to make time to meet visiting colleagues and to reach out to local scientists while travelling. He recommends caution if buying carbon offsets - scientists should scrutinize programmes to verify them and ensure that they actually prevent emissions.

Scientific organizations that host major meetings could also take steps to reduce carbon footprints. In a 2011 study ${ }^{6}$, Alexandra PonetteGonzález, a geographer at the University of North Texas in Denton, and her colleagues considered what would happen if organizations alternated large national or international meetings with regional ones every other year. They found that this could reduce conference-related carbon emissions by up to $73 \%$, and that choosing central meeting locations could save further. for the conservation scientists ${ }^{2}$. Flying less thus much.” Wilde runs a blog called 'Flying Less'

Ponette-González has cut back on her own conference travel. She recently attended a nearby meeting to establish more local connections and learn about science in her own backyard. However, she acknowledges that tenured professors such as herself have the luxury of choosing conferences and turning down speaking invitations. She does not recommend that early-career scientists skip opportunities to show off their work. Researchers in isolated locations also benefit from networking opportunities, she says, and may have a harder time accessing alternative forms of transportation.

One obvious solution to this trade-off is virtual meetings, but they have been slow to catch on. Many scientists say that although webinar technology has come a long way, it still can't provide opportunities for the casual one-on-one interactions that make conferences so valuable.

People such as Chris Welch are trying to change that. When Welch ran the technologyinnovation group of health-care giant Merck, based in Kenilworth,
New Jersey, he hired web designers to build a virtual conference, and hosted a meeting there. Using avatars and microphones, participants moved

"It's a personal level of being consistent with why they are a scientist in the first place."

between posters, entering multiparticipant conversations inside a blue circle surrounding the presenter, or sitting in virtual chairs to chat in the 'conversation zone'.

The lack of virtual halls available to rent for web-based conferences may have prevented them from gaining popularity, Welch suspects. However, Linden Lab in San Francisco, California, which previously developed a virtual conferencing service called Second Life, is preparing to launch a beta version of a platform called Sansar. Users will be able to create custom

\section{FLIGHT EMISSIONS}

Researchers worldwide routinely fly to scientific conferences to present papers, learn of new findings and make connections. But there is an environmental cost to those flights. Here are the average carbon dioxide emissions for several common flights, in kilograms of $\mathrm{CO}_{2}$ per round-trip economy ticket.

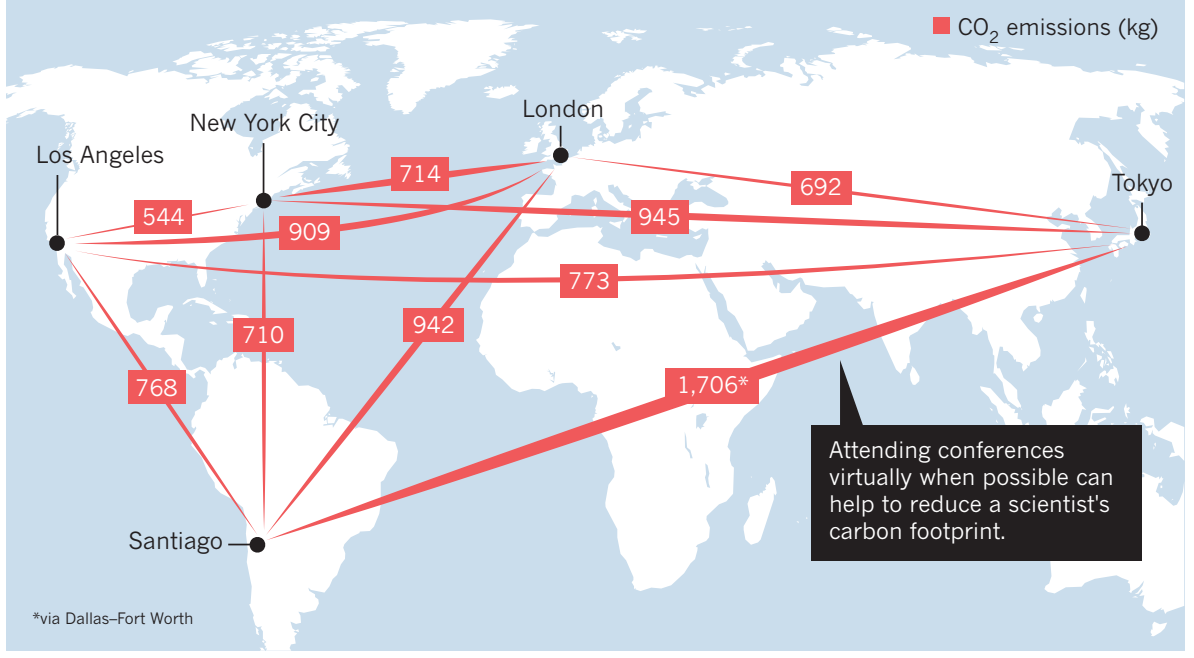

virtual-reality experiences, including meetings.

As technology improves, Welch says, the benefits of virtual meetings will outweigh the downsides. A follow-up survey found that people enjoyed his virtual meeting and were more likely to approach senior executives at it than in real life ${ }^{7}$. Virtual meetings also take up less time and are cheaper to attend, which makes them more accessible to early-career scientists and those in far-flung locations or with tight budgets. "The more equitable participation is a really valid point for today's science," Welch says.

\section{TREAD LIGHTLY}

Many scientists also fly to do fieldwork, and Wilde says that he would never encourage people to give up important research that requires them to travel. However, a growing number of scientists are finding low-impact ways to do that work. For example, Osterberg wanted to cut his environmental impact when drilling ice cores. He was delighted when, in 2012, he got permission to drill inside Alaska's Denali National Park - but he wanted to avoid using a petrol-powered generator. So he asked engineers who design drills for US coring operations to develop a low-impact rig. They delivered. In 2013, Osterberg's team successfully drilled two 200-plus-metre cores by drawing power from only a few solar panels, a wind turbine and a bank of batteries.

PhD student Elly Knight, an ecologist at the University of Alberta in Edmonton, Canada, opted for leg power to do her work. Last summer, she travelled by bicycle to set up recording devices to monitor common nighthawks (Chordeiles minor) in Alberta's boreal forest. A raging wildfire had led to a ban on fourwheeled vehicles, so she arrived at the idea of using fat-wheeled bikes to negotiate the rough, sandy landscape. Her university's sustainability office helped her to draft a letter to local bike shops, which lent her the bicycles for free.

Jason Box, a climatologist at the Geological Survey of Denmark and Greenland in Copenhagen, has used skis instead of helicopters for his work studying the Greenland ice sheet. Box also directs a crowd-funded research initiative called Dark Snow, which is helping to support a six-week expedition on the ice, now under way, in which scientists traverse the ice sheet on a zero-emissions vehicle called the WindSled. The vehicle was modelled on Inuit dog sledges, and is pulled by a massive kite.

The WindSled has made several successful trips across Greenland and Antarctica and has supported one previous scientific expedition, says Box. The current trip will offer a prime opportunity to further demonstrate the vehicle's capacity to serve as a low-carbon scientific platform. Researchers will collect shallow cores as they travel 1,200 kilometres across the ice sheet. Box says that using the WindSled instead of a ski plane saves 100 barrels of fuel.

Teams are also looking for ways to shrink the carbon footprints of their labs. At Georgia Tech, 
